\title{
Beyond oestrogens: towards a broader evaluation of the hormone profile in pulmonary arterial hypertension
}

\author{
Jessica B. Badlam ${ }^{1}$ and Eric D. Austin² \\ Affiliations: ${ }^{1}$ University of Colorado at Denver - Anschutz Medical Campus, Aurora, CO, USA. ${ }^{2}$ Dept of \\ Pediatrics, Vanderbilt University Medical Center, Nashville, TN, USA. \\ Correspondence: Eric D. Austin, Dept of Pediatrics, Division of Pulmonary, Allergy, and Immunology \\ Medicine, DD-2205 Medical Center North, Vanderbilt University School of Medicine, Nashville, TN, 37232-
} 2578, USA. E-mail: eric.austinavanderbilt.edu

@ERSpublications

Baird and colleagues contribute further evidence that the justification for sex-associated investigations in pulmonary arterial hypertension extend beyond oestrogen signalling. Evaluation of the entire steroid hormone milieu is crucial. http://ow.ly/7wbz30kp5VQ

Cite this article as: Badlam JB, Austin ED. Beyond oestrogens: towards a broader evaluation of the hormone profile in pulmonary arterial hypertension. Eur Respir J 2018; 51: 1801058 [https://doi.org/ 10.1183/13993003.01058-2018].

For nearly all forms of group 1 pulmonary hypertension (pulmonary arterial hypertension; PAH), incident and prevalent patients are more likely to be female $[1,2]$. The skew toward the female sex has long prompted an interest in the sex hormones as contributors to disease pathogenesis, with a particular interest in oestrogens. In 2010, ToFovic [3] employed the term "oestrogen paradox" based upon a perceived discrepancy: while $\mathrm{PAH}$ is a female-prevalent disease in humans, many (but not all) animal models demonstrate a protective effect of being female. However, over time, the intent of the "oestrogen paradox" has been modified to incorporate a growing body of human data concerning sex and PAH. In particular, the female predominance in $\mathrm{PAH}$ incidence is lower than the female predominance among prevalent cases; and, females appear to tolerate right ventricular (RV) stress and live longer than older males, if not all males [4-9]. While comprehensive data to determine why females may tolerate a hypertensive pulmonary vasculature better than males is lacking, growing information suggests that either baseline RV performance, and/or ability to adapt to stress with or without PAH therapy, may favour the female heart [10-14].

The sex discrepancy in PAH has triggered a robust interest in the contribution of sex hormones to PAH pathogenesis as well as the RV response to stress, such as due to PAH. Over the past decade, multiple studies in total suggest an association between PAH and a systemic profile of higher oestrogens among those with and without underlying susceptibility to $\mathrm{PAH}$, such as BMPR2 mutations and connective tissue disease [15-18]. For example, Ventetuolo et al. [16] recently showed that female sex hormone levels associate with the risk of $\mathrm{PAH}$ in men; specifically, high oestradiol (E2) levels in men conferred an increased risk of PAH (50-fold increased risk for a 1-unit increase in E2) as well as reduced 6-min-walk distance (6MWD) among male PAH patients. That study also expanded our consideration of the hormonal profile in PAH, finding that higher dehydroepiandrosterone sulfate (DHEA-S) levels associated with reduced risk of PAH as well as lower right atrial pressure and pulmonary vascular resistance among males with PAH. 
The mounting preclinical and clinical evidence that sex hormones are perturbed in PAH (recent reviews include those by Foderaro and Ventetuolo [19], Tofovic and Jackson [20], and Lahm and Kawut [21]) has prompted efforts to repurpose pharmaceuticals directed at reducing the oestrogen milieu in PAH in humans. KAwUT et al. [22] recently completed an early phase II randomised clinical trial of aromatase inhibition using anastrozole in postmenopausal women and men with $\mathrm{PAH}$; the results of that study, including patient toleration, reduction in circulating E2 levels, and modest improvement in 6MWD, support the concept that oestrogen antagonism warrants further study. In addition to a larger phase II multicentre study of anastrozole (NCT03229499) currently enrolling, the National Heart, Lung, and Blood Institute (NHLBI) recently funded studies of oestrogen receptor antagonism in PAH using tamoxifen (NCT03528902) and fulvestrant (NCT02911844). But oestrogens are not the only focus of study from the sex hormone milieu; prior mechanistic data from animals showed that DHEA increased soluble guanylate cyclase levels in the pulmonary vasculature and reversed established hypoxic pulmonary hypertension [23, 24]. In fact, the NHLBI recently funded a proof-of-concept trial to study the impact of DHEA treatment on the $\mathrm{RV}$ in PAH patients.

In the current issue of the European Respiratory Journal, BAIRD et al. [25] continue the exploration beyond oestrogens into a population of post-menopausal females to provide further evidence that the sex hormone milieu is altered in patients with PAH. In contrast to their previous study of males, women aged over 55 years were the focus of this study, which assessed E2, DHEA, testosterone, bioavailable testosterone, progesterone, and sex hormone binding globulin levels compared to controls derived from the Multi-Ethnic Study of Atherosclerosis (MESA)-RV Study [26]. Unlike E2 or progesterone, statistical modelling demonstrated that every unit decrease in DHEA-S, total testosterone, bioavailable testosterone, and SHBG increased the odds of PAH 3- to 4-fold, regardless of participant age and body mass index (BMI). By modelling hormone levels and clinical metrics, they demonstrated that reduction in DHEA-S levels most consistently associated with metrics of clinical worsening, including $6 \mathrm{MWD}$, right atrial pressure, pulmonary vascular resistance, and mean pulmonary artery pressure, as well as the risk of death (median follow up of 2 years). While not associated with survival, higher levels of E2 did associate with metrics of severity, including a lower functional class and 6MWD.

Multiple strengths characterised this case-control study, including the large number of subjects studied, as well as the use of the carefully characterised MESA participants as controls. Given the importance of age and BMI to hormone levels, matching according to these parameters was crucial to the methodological approach. The large sample size allowed the authors to examine relationships among the hormones, with

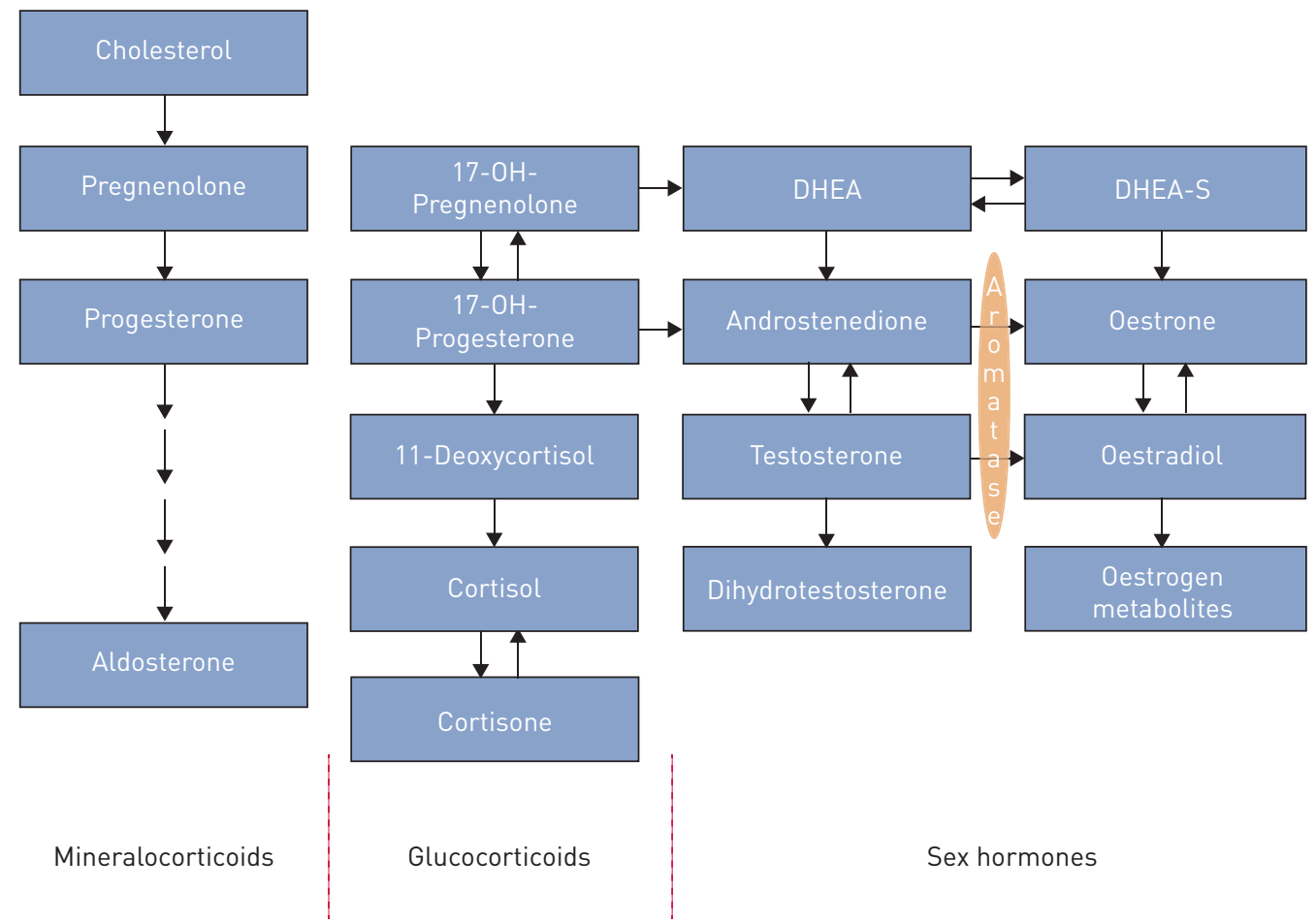

FIGURE 1 Simplified scheme of steroid hormone synthesis. DHEA: dehydroepiandrosterone; DHEA-S: dehydroepiandrosterone sulfate. Adapted from [35]. 
no evidence of association or effect modification detected among the hormones despite the fact that DHEA is a known precursor of both androgens and oestrogens [27]. By extending our understanding of the human PAH condition, this study supports the conduct of clinical trials to study the benefit and risks of modifying oestrogen activity. In addition, their findings highlight our need to look beyond female oestrogens, including the potential importance of DHEA-S to PAH pathogenesis and progression [16].

However, multiple opportunities for exploration remain following this study, many of which were appropriately noted by the authors. While difficult to perform, longitudinal studies of sex hormone levels in PAH are needed, ideally starting with treatment-naïve incident cases followed over time; the current study was biased toward prevalent cases. Such studies would ideally include more depth of investigations with regard to RV function and adaptation to stress over time, and integrate a broader array of biochemical metrics (e.g. genomic, transcriptomic, and proteomic data). It is notable, for example, given the known associations between PAH and the pregnant and post-partum state [28], that DHEA-S levels are lower in pregnant females compared to those in the non-pregnant state [29]. In addition, if hormone levels such as DHEA-S influence RV adaptation to stress, other groups of pulmonary hypertension should be studied to determine if DHEA-S equally influences clinical metrics and mortality. Finally, while a significant challenge due to cyclic alterations, the inclusion of pre-menopausal females in studies of sex hormones will be a significant contribution. Regardless, the current study significantly advances our understanding of PAH broadly with regard to sex hormone levels, and reinforces the need to evaluate beyond oestrogens.

While systemic levels are important, circulating sex hormone levels may not accurately reflect activity at the tissue, or even cell-specific, level [30]. Furthermore, sex hormones are not the only hormones relevant to $\mathrm{PAH}$ pathogenesis. In fact, the steroidogenic hormones derived from cholesterol, including but not limited to sex hormones, undergo an intimately related process of synthesis and metabolism (figure 1). For example, mineralocorticoids, in particular aldosterone, have been implicated in PAH via the promotion of pulmonary vascular remodelling and fibrosis [31-33]. Likewise, metabolic irregularities including insulin resistance and abnormal fatty acid metabolism may be characteristic of PAH (recently reviewed by TALATI and HemNes [34]); to what, if any, degree steroidogenic glucocorticoids contribute to this process has yet to be elucidated.

The current study, as well as additional studies, have advanced the paradigm of PAH pathogenesis and progression, and support novel strategies for PAH management currently under investigation. In addition, there is now ample data to suggest that justification for sex-associated investigations in PAH extend beyond oestrogen signalling. While it has served the field well, we respectfully suggest that it is time to retire the term "oestrogen paradox" in $\mathrm{PAH}$, and re-focus our thoughts on the entire sex hormone pathway, and, perhaps, integrate sex hormones more broadly within the context of all steroidogenic hormones. Whether its original intent, or updated meaning, this study by BAIRD et al. [25] highlights the fact that the "oestrogen paradox" now insufficiently describes sex-associated differences in PAH. A more inclusive approach will allow us to more effectively, and safely, modify hormone signalling in PAH.

Conflict of interest: None declared.

Support statement: Funding was provided by NIH R01 HL 134802 (E.D. Austin). Funding information for this article has been deposited with the Crossref Funder Registry.

\section{References}

1 Humbert M, Sitbon O, Chaouat A, et al. Pulmonary arterial hypertension in France: results from a national registry. Am J Respir Crit Care Med 2006; 173: 1023-1030.

2 Badesch DB, Raskob GE, Elliott CG, et al. Pulmonary arterial hypertension: baseline characteristics from the REVEAL Registry. Chest 2010; 137: 376-387.

3 Tofovic SP. Estrogens and development of pulmonary hypertension: interaction of estradiol metabolism and pulmonary vascular disease. J Cardiovasc Pharmacol 2010; 56: 696-708.

4 Humbert M, Sitbon O, Chaouat A, et al. Survival in patients with idiopathic, familial, and anorexigen-associated pulmonary arterial hypertension in the modern management era. Circulation 2010; 122: 156-163.

5 Benza RL, Miller DP, Gomberg-Maitland M, et al. Predicting survival in pulmonary arterial hypertension: insights from the Registry to Evaluate Early and Long-Term Pulmonary Arterial Hypertension Disease Management (REVEAL). Circulation 2010; 122: 164-172.

6 Shapiro S, Traiger GL, Turner M, et al. Sex differences in the diagnosis, treatment, and outcome of patients with pulmonary arterial hypertension enrolled in the registry to evaluate early and long-term pulmonary arterial hypertension disease management. Chest 2012; 141: 363-373.

7 Farber HW, Miller DP, Poms AD, et al. Five-year outcomes of patients enrolled in the REVEAL Registry. Chest 2015; 148: 1043-1054.

8 Chung L, Domsic RT, Lingala B, et al. Survival and predictors of mortality in systemic sclerosis-associated pulmonary arterial hypertension: outcomes from the pulmonary hypertension assessment and recognition of outcomes in scleroderma registry. Arthritis Care Res (Hoboken) 2014; 66: 489-495. 
9 Humbert M, Sitbon O, Yaici A, et al. Survival in incident and prevalent cohorts of patients with pulmonary arterial hypertension. Eur Respir J 2010; 36: 549-555.

10 Kawut SM, Al-Naamani N, Agerstrand C, et al. Determinants of right ventricular ejection fraction in pulmonary arterial hypertension. Chest 2009; 135: 752-759.

11 Jacobs W, van de Veerdonk MC, Trip P, et al. The right ventricle explains sex differences in survival in idiopathic pulmonary arterial hypertension. Chest 2014; 145: 1230-1236.

12 Ventetuolo CE, Hess E, Austin ED, et al. Sex-based differences in veterans with pulmonary hypertension: results from the veterans affairs-clinical assessment reporting and tracking database. PLoS One 2017; 12: e0187734.

13 Gabler NB, French B, Strom BL, et al. Race and sex differences in response to endothelin receptor antagonists for pulmonary arterial hypertension. Chest 2012; 141: 20-26.

14 Mathai SC, Hassoun PM, Puhan MA, et al. Sex differences in response to tadalafil in pulmonary arterial hypertension. Chest 2015; 147: 188-197.

15 Austin ED, Cogan JD, West JD, et al. Alterations in oestrogen metabolism: implications for higher penetrance of familial pulmonary arterial hypertension in females. Eur Respir J 2009; 34: 1093-1099.

16 Ventetuolo CE, Baird GL, Barr RG, et al. Higher estradiol and lower dehydroepiandrosterone-sulfate levels are associated with pulmonary arterial hypertension in men. Am J Respir Crit Care Med 2016; 193: 1168-1175.

17 Fessel JP, Chen X, Frump A, et al. Interaction between bone morphogenetic protein receptor type 2 and estrogenic compounds in pulmonary arterial hypertension. Pulm Circ 2013; 3: 564-577.

18 Roberts KE, Fallon MB, Krowka MJ, et al. Genetic risk factors for portopulmonary hypertension in patients with advanced liver disease. Am J Respir Crit Care Med 2009; 179: 835-842.

19 Foderaro A, Ventetuolo CE. Pulmonary arterial hypertension and the sex hormone paradox. Curr Hypertens Rep 2016; 18: 84 .

20 Tofovic SP, Jackson EK. Estrogens in men: another layer of complexity of estradiol metabolism in pulmonary hypertension. Am I Respir Crit Care Med 2016; 193: 1087-1090.

21 Lahm T, Kawut SM. Inhibiting oestrogen signalling in pulmonary arterial hypertension: sex, drugs and research. Eur Respir J 2017; 50: 1700986.

22 Kawut SM, Archer-Chicko CL, DiMichele A, et al. Anastrozole in pulmonary arterial hypertension (AIPH): a randomized, double-blind placebo-controlled trial. Am J Respir Crit Care Med 2017; 195: 360-368.

23 Homma N, Nagaoka T, Karoor V, et al. Involvement of RhoA/Rho kinase signaling in protection against monocrotaline-induced pulmonary hypertension in pneumonectomized rats by dehydroepiandrosterone. Am $J$ Physiol Lung Cell Mol Physiol 2008; 295: L71-L78.

24 Oka M, Karoor V, Homma N, et al. Dehydroepiandrosterone upregulates soluble guanylate cyclase and inhibits hypoxic pulmonary hypertension. Cardiovasc Res 2007; 74: 377-387.

25 Baird GL, Archer-Chicko C, Barr RG, et al. Lower DHEA-S levels predict disease and worse outcomes in post-menopausal women with idiopathic, connective tissue disease- and congenital heart disease-associated pulmonary arterial hypertension. Eur Respir J 2018; 51: 1800467.

26 Kawut SM, Lima JA, Barr RG, et al. Sex and race differences in right ventricular structure and function: the multi-ethnic study of atherosclerosis-right ventricle study. Circulation 2011; 123: 2542-2551.

27 Savineau JP, Marthan R, Dumas de la Roque E. Role of DHEA in cardiovascular diseases. Biochem Pharmacol 2013; 85: 718-726.

28 Olsson KM, Channick R. Pregnancy in pulmonary arterial hypertension. Eur Respir Rev 2016; 25: 431-437.

29 Makieva S, Saunders PT, Norman JE. Androgens in pregnancy: roles in parturition. Hum Reprod Update 2014; 20: 542-559.

30 Regitz-Zagrosek V, Kararigas G. Mechanistic pathways of sex differences in cardiovascular disease. Physiol Rev 2017; 97: 1-37.

31 Maron BA, Oldham WM, Chan SY, et al. Upregulation of steroidogenic acute regulatory protein by hypoxia stimulates aldosterone synthesis in pulmonary artery endothelial cells to promote pulmonary vascular fibrosis. Circulation 2014; 130: 168-179.

32 Aghamohammadzadeh R, Zhang YY, Stephens TE, et al. Up-regulation of the mammalian target of rapamycin complex 1 subunit Raptor by aldosterone induces abnormal pulmonary artery smooth muscle cell survival patterns to promote pulmonary arterial hypertension. FASEB J 2016; 30: 2511-2527.

33 Boehm M, Arnold N, Braithwaite A, et al. Eplerenone attenuates pathological pulmonary vascular rather than right ventricular remodeling in pulmonary arterial hypertension. BMC Pulm Med 2018; 18: 41.

34 Talati M, Hemnes A. Fatty acid metabolism in pulmonary arterial hypertension: role in right ventricular dysfunction and hypertrophy. Pulm Circ 2015; 5: 269-278.

35 Turcu AF, Auchus RJ. Adrenal steroidogenesis and congenital adrenal hyperplasia. Endocrinol Metab Clin North Am 2015; 44: 275-296. 